\title{
Data-Based Modelling of Ship Propulsion for A 2500 TEU Feeder Container Ship
}

\author{
Jefferson Marcel Soadamara ${ }^{1}$, Wolfgang Busse ${ }^{2}$, Karsten Wehner ${ }^{3}$ \\ (Received: 31 August 2020 / Revised: 08 September 2020 / Accepted: 10 December 2020)
}

\begin{abstract}
The focus of this paper is on the creation of a data-based model to estimate the power increase or speed loss due to the influence of weather, by using resistance estimation theories and added resistance approximation methods along with additional assisting tools. Furthermore, a theoretical simulation is done in order to benchmark and correct the model setup. The analysis of simulation results shows that at the available data range, the model proves reasonably precise within its capabilities, for academic applications. The general behavior of the model complies with common ship theory, however, does not perfectly resemble the speed-power relation of the ship's recorded data averages. The analysis suggests that the model is most compatible with the shipload draft of 9,0 to 9,5 meters and within the speed of 19 to 22 knots. The lack of data outside the typical operating range disables the ability to verify the model correspondingly. The theoretical simulation proves valuable in assessing ship data-based models.
\end{abstract}

Keywords — added resistance, data-based modeling, ship propulsion, voyage analysis, weather influence.

\section{INTRODUCTION}

$\mathrm{T}_{\mathrm{h}}$ he design and operation of ships worldwide, especially cargo ships, is increasing rapidly. One of the most focused aspects is the economical side. One of the main concerns of the shipping industry is rough weather. Basically, the worse the weather gets, the higher the risk is, in terms of both safety and economically. is, in terms of both safety and economically. is, in terms of both safety and economically.

Depending on the direction and magnitude, strong gusts of wind can affect the body of the ship above the waterline, causing higher air resistance. Theoretically, the stronger the wind gets, the larger the strength of the waves. These occurrences cause an increase in the added resistance of the vessel. In larger magnitudes, these factors can cause a ship to run inefficiently due to the large power it requires in these conditions.

Ultimately, the effects of waves on the ship's hull directly affect the propulsion system. Pitching and rolling of the ship, and any imbalances of the ship's level may cause either addition of wake [1], fluctuations in the propeller efficiency, and occurrence of propeller emergence. Thus, it is logical for a vessel to avoid traveling in such conditions.

Since the release of the EEDI and EEOI requirements by IMO, there is an environmental goal in the maritime world to reduce the carbon emission emitted by the shipping industry. With the existing practice of weather routing, it is possible to minimize cost and uphold safety in terms of dealing with weather.

Jefferson Marcel Soadamara is with Department of Marine Engineering, Institut Teknologi Sepuluh Nopember, Surabaya, 60111, Indonesia. E-mail: jeffsoadamara@gmail.com

Wolfgang Busse, Department of Maritime Studies, Hochschule Wismar, Rostock, 18119, Germany. E-mail: wolfgang.busse@hswismar.de

Karsten Wehner, Department of Maritime Studies, Hochschule Wismar, Rostock, 18119, Germany. E-mail: karsten.wehner@hswismar.de
Recording the voyage data and research enables the possibility to accurately predict the required power for a vessel, compared to just using a "weather margin" to compensate for rough weather. For the operation side, it assists in forming the voyage plan, to determine where the ship should sail and which direction it should move in order to minimize the impact of weather, consequently increasing the ship's efficiency and reduces the environmental waste.

During an observation of ship voyage recorded data, it is often found that data is incomplete. Data from ship $\operatorname{logs}$ such as the noon report often only record the observed power and speed. To assist in the evaluation of the voyages, it is necessary to create a theoretical estimation model to predict ship power-speed relation in various weather conditions.

In regards to that issue, this paper focuses on creating a data-based model that can predict power increase or speed loss due to wind and waves influences. The model will be applied to the theoretical simulation, enabling assessment and benchmarking with actual recorded ship data within academically reasonable error tolerance, which in result will develop an understanding of ship operation data processing and contribute towards its development.

\section{METHOD}

\section{A. Ship Data}

One of the goals is to benchmark the model created with the actual data processed. The vessels which are discussed in this analysis are two built ships (Liberta and Impala) of the same design with data limited to:

- Date and Time

- Engine speed (rpm)

- Brake power $(\mathrm{kW})$

- Fuel consumption $(\mathrm{kg} / \mathrm{h})$

- Vessel speed (Kn)

However, the focus is primarily on the engine power and travel speed of the ship. This data is obtained from the noon report recordings of the actual voyages.

To assist in calculations and creation of framework the basic information and dimensions are also obtained 
alongside typical assumptions as seen in Table 1.

TABLE 1.

GENERAL INFORMATION OF ANALYZED VESSEL.

\begin{tabular}{|c|c|c|}
\hline \multicolumn{3}{|c|}{ Container Vessel } \\
\hline LOA & $\mathrm{m}$ & 208.11 \\
\hline LPP & $\mathrm{m}$ & 197,19 \\
\hline LWL & $\mathrm{m}$ & 199.2 \\
\hline Tmax & $\mathrm{m}$ & 11.4 \\
\hline $\mathrm{H}$ & $\mathrm{m}$ & 16.4 \\
\hline B & $\mathrm{m}$ & 29.8 \\
\hline $\mathrm{CB}$ & - & 0.65 \\
\hline DWT at Tmax & $\mathrm{t}$ & 34000 \\
\hline Weight / Light Displacement & $\mathrm{t}$ & 11078 \\
\hline Loaded Displacement & $\mathrm{t}$ & 45078 \\
\hline Wake fraction & $\mathrm{kW}$ & 19810 \\
\hline Hull efficiency & $\mathrm{m}^{3}$ & 43978.5 \\
\hline
\end{tabular}

Ship recorded voyage data is processed into a plot which allows a more focused scope of research, by understanding the average behavior of the ship operation.

The ship power-speed relation is expressed by a coefficient of power against speed which is applied to the recorded ship voyage data. The relation is expressed by:

$P=c * V^{n}$
Where $P$ and $V$ are respectively; ship power in $\mathrm{kW}$ and vessel speed in knots, $c$ is the coefficient representing the ratio, and $n$ denotes the behavior of the power-speed relation, in this case, is the value of 3 .

In order to support the analysis of the paper, a typical container ship computer model is generated and converted to a CAD model for an overall approximation of the hull form.

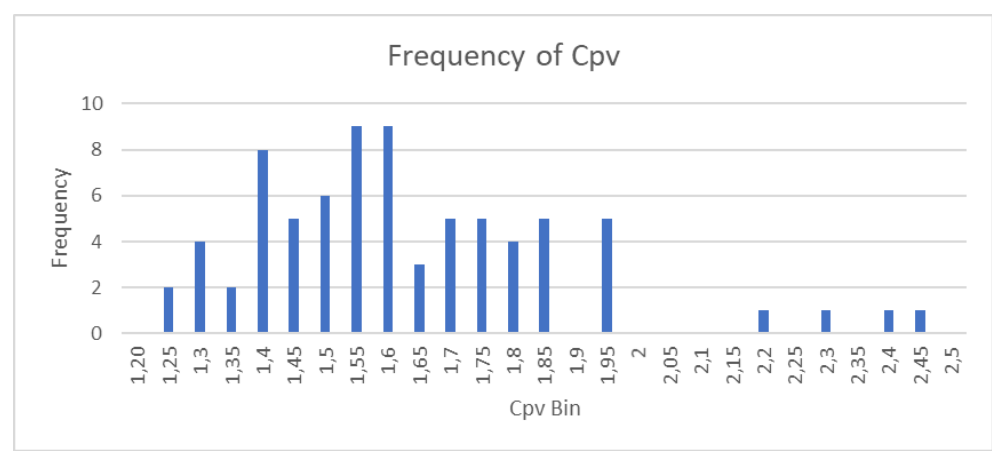

Figure. 1. Liberta $\mathrm{C}_{\mathrm{pv}}$ count

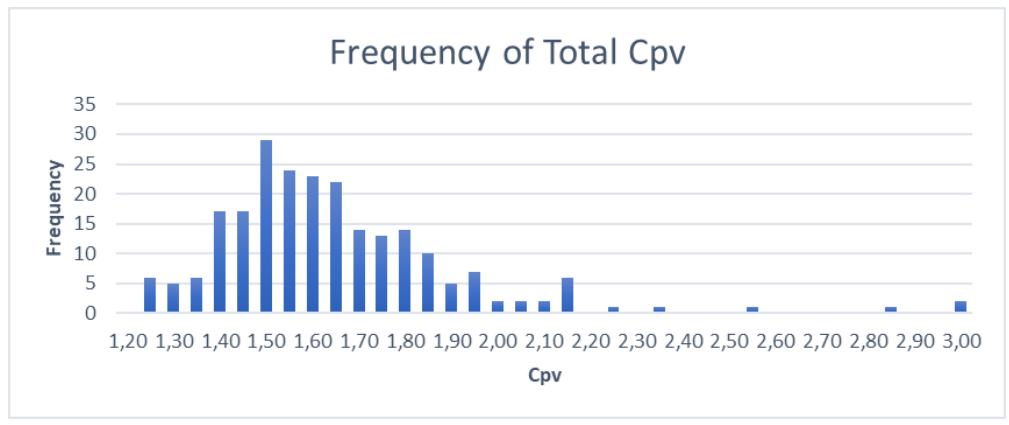

Figure. 2. Impala $\mathrm{C}_{\mathrm{pv}}$ count

As seen in Figure 1. and Figure 2., the voyage recordings show that during most operations the $\mathrm{C}_{\mathrm{pv}}$ is between 1.40 to 1.65. This information can be used to narrow down the analysis, by constraining the area for simulation to this range of resultant $\mathrm{C}_{\mathrm{pv}}$. It is also clear that Liberta has a larger pool of data samples.
B. Estimation of Calm Water Resistance and Added Resistance

1) Estimation of Calm-Water Resistance

When considering the influence of weather on a vessel, it is intuitive to first obtain the ship resistance in calm water. The methods applied in this paper are the Guldhammer-Harvald and Holtrop resistance estimation 
methods, along with some modifications from recent studies on those classic methods.

Essentially, the Guldhammer method results in a total resistance coefficient, $C_{T}$ which will be used to find the total resistance $\mathrm{R}_{\mathrm{T}}[2]$ :

$R_{T}=C_{T}\left(0,5 \times \rho \times V^{2} \times S\right)$

Where $\mathrm{V}$ is the vessel speed, and $\mathrm{S}$ is the wetted surface area of the ship. The total resistance coefficient, $C_{T}$ is a multiplication of a series of coefficients, expressed by:

$$
C_{T}=C_{F}+C_{R}+C_{A}
$$

Where it consists of frictional resistance coefficient $\left(C_{F}\right)$, residual resistance coefficient $\left(C_{R}\right)$, and incremental resistance coefficient $\left(C_{A}\right)$ which is minorly affected by the ship steering resistance coefficient $\left(C_{A S}\right)$ and air resistance coefficient $\left(C_{A A}\right)$.

The standard Harvald method does not consider the effect of the bulbous bow, as it is assumed the ship has a standard nonbulbous bow [5]. In a more recent study on

TABLE 2. the influence of bulbous bow, it is found that from the analysis of multiple model tests, the bulbous bow correction of residual resistance coefficient $C_{R}$ is also a function of Froude Number [5]:

$\Delta C_{R, b u l b}=(250 \times F n-90) \cdot \frac{C_{R \text { Harvald NO bulbous bow }}}{100}$

The second method as a comparison for the approximation of calm water resistance is the HoltropMennen method which is [6]:

$R_{T}=R_{F}\left(1+k_{1}\right)+R_{A P P}+R_{W}+R_{B}+R_{T R}+R_{A}$

Where $R_{F}$ is the frictional resistance, $\left(1+k_{1}\right)$ represents the ship hull form, $R_{A P P}$ represents the appendages resistance, $R_{W}$ represents the wave-making and wavebreaking resistance, $R_{B}$ is the effect of the bulbous bow near-surface, $R_{T R}$ is the effect of the immersed transom, and $\mathrm{R}_{\mathrm{A}}$ is the incremental resistance.

RESULTS OF CALM WATER RESISTANCE ESTIMATION.

\begin{tabular}{|c|c|c|c|c|c|}
\hline \multicolumn{6}{|c|}{ Calm Water Resistance Estimation } \\
\hline V (knots) & $\mathrm{V}(\mathrm{m} / \mathrm{s})$ & $\begin{array}{l}\text { Rt [Harvald] (kN) } \\
\text { at } 17 \mathrm{deg} \text {. celcius } \\
\text { sea temp. }\end{array}$ & $\begin{array}{l}\text { Rt [Holtrop] (kN) } \\
\text { at } 17 \text { deg. celcius } \\
\text { sea temp. }\end{array}$ & $\begin{array}{l}\text { Rt [Harvald] }(\mathrm{kN}) \\
\text { at } 6 \text { deg. celcius } \\
\text { sea temp. }\end{array}$ & $\begin{array}{l}\text { Rt [Holtrop] }(\mathrm{kN}) \\
\text { at } 6 \mathrm{deg} \text {. celcius } \\
\text { sea temp. }\end{array}$ \\
\hline 21 & 10.80 & 1298.78 & 1354.56 & 1327.20 & 1383.96 \\
\hline 20 & 10.28 & 1077.12 & 1216.21 & 1102.80 & 1243.11 \\
\hline 19 & 9.77 & 914.32 & 1029.81 & 937.52 & 1054.31 \\
\hline 18 & 9.26 & 779.84 & 853.33 & 800.72 & 875.54 \\
\hline 17 & 8.74 & 680.54 & 738.95 & 699.30 & 758.96 \\
\hline 16 & 8.23 & 584.68 & 632.10 & 601.40 & 650.04 \\
\hline 13 & 6.68 & 368.62 & 395.41 & 380.00 & 407.71 \\
\hline 10 & 5.14 & 218.57 & 235.59 & 225.61 & 243.24 \\
\hline 7 & 3.60 & 108.46 & 119.67 & 112.13 & 123.68 \\
\hline 4 & 2.05 & 36.72 & 42.89 & 38.05 & 44.35 \\
\hline 1 & 0.51 & 2.64 & 3.28 & 2.75 & 3.40 \\
\hline 0 & 0.00 & 0.00 & 0.00 & 0.00 & 0.00 \\
\hline
\end{tabular}

loss, which is the involuntary reduction of the calm water

For a comparison example, a total of the propulsive efficiency multiplication is assumed 0.723. The example from classic resistance theory will be taken at Vs of 21 knots with a resistance of $1298.784 \mathrm{kN}$ (from the first method). The resulting brake horsepower is $19407 \mathrm{~kW}$.

A sample from the sea trial results of the ship, "Test No. 16" at $16072 \mathrm{~kW}$ indic. / $14840 \mathrm{~kW}_{\text {eff }}$ is selected, where the general direction of weather is bow waves, with relatively small wind and waves strength.

When compared with the resultative brake horsepower estimation, the results suggest that the actual required power is of the ship is lower than the results of using the current setup with the calm water resistance estimation theories. The calculations in Table 2., however, refer to the ship conditions at the maximum load draft.

2) Approximation of Added Resistance

Kwon's method of predicting added resistance is also a general approach for a large variety of commercial displacement type ships. Even so, Kwon's approach considers the ship type, load condition, and the ship's general dimension (in the form of the coefficient block). The added resistance is expressed in the value of speed vessel speed to the vessel speed in wind and waves. The speed loss is formulated as [11]:

$\frac{\Delta V}{V_{1}} 100 \%=C_{\beta} C_{U} C_{F o r m}$

In the approximation, the travel speed of the vessel, expressed in Froude Number $F_{n}$, is represented in the coefficient $C_{U}$. This also considers the block coefficient of the ship and it's loading conditions. The directional angle of the wind and waves is expressed by the coefficient $C_{\beta}$ with its magnitude determined by the Beaufort Number. The type of the vessel is expressed by the coefficient $C_{\text {Form }}$ and is also determined by the displacement.

\section{Creation of Model-Simulation Setup}

1) Input Section

- Initial Forward Speed $V_{\text {s init }}$ The initial forward speed refers to the desired travel speed of the vessel that isn't affected by the change in weather conditions. The model 
assumes the hull and machinery are in optimal conditions, therefore influence towards speed from such factors is ignored.

- Beaufort Number

The weather conditions are represented in the Beaufort Number, which mainly determines the magnitude of the speed loss or power increase.

- Angle of Attack

The overall angle of the wind and waves which also determine the severity and nature of the weather influence.

- Draft

Conditions of a loaded container ship are unlikely always the same, however, the change in draft load influence the displacement of the ship, affecting the total resistance and consequently increasing or decreasing the propulsive power requirement.

- Propulsive Efficiencies

Propulsive efficiencies refer to the efficiencies of the propulsive coefficient, the gearbox, and shaft efficiency which are determinants of the transition between effective horsepower (EHP), and brake horsepower (BHP). In this case, the propulsive efficiencies are held as constant values (not generated variously during simulation).

2) Transfer function

- $\quad$ Displacement Volume ( $\nabla)$

The displacement volume is the ship's displacement in volume $\mathrm{m}^{3}$ and is essential to the determination of the ship form coefficient.

- Corresponding Resistance

The corresponding resistance refers to the initial resistance which is the approximation of the calm water resistance required under certain conditions and a specific travel speed.
- $\quad$ Speed Reduction Coefficient $\left(\mathrm{C}_{\mathrm{U}}\right)$

The speed reduction coefficient relates to the speed of the vessel which is expressed in the value of the Froude Number $\left(F_{n}\right)$. The value is also determined by the ship's coefficient block.

- Direction Reduction Coefficient $\left(C_{\beta}\right)$ The direction reduction coefficient, selfexplanatory, relates to the overall angle of the weather, with respect to the ship's bow, which is determinant towards the value of the coefficient itself.

- $\quad$ Ship Form Coefficient $\left(C_{\text {form }}\right)$

The ship form coefficient is dependent on the ship type, the load conditions, the displacement volume $(\nabla)$, and the weather magnitude on the Beaufort Scale.

- $\quad$ Percentage Speed Loss

The results of the approximation of weather influence are represented in the form of a percentage of speed loss according to Kwon's method.

- Initial Power Requirement

This is the estimated engine brake power when the ship is subjected to the initial speed input in calm water with optimal conditions.

3) Output section

- The reduction of speed from the desired travel speed if a decision to remain at the same initial power is made.

- The increase of required engine power from the initial power setting if a decision to remain at the same initial speed is made.

An overview of the model-simulation setup can be seen in Figure 3.

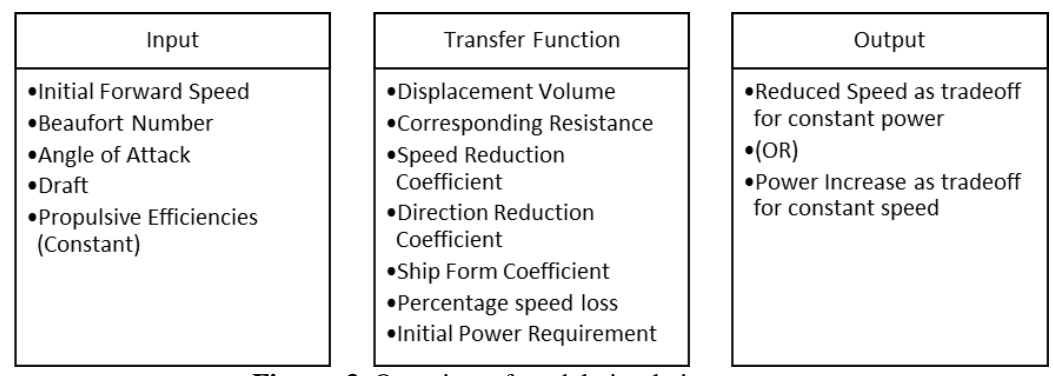

Figure. 3. Overview of model-simulation concept

The model-simulation concept is created in a spreadsheet program by generating random numbers on the input side (except the propulsive efficiencies constant), with simulation parameters in the range shown in Table 3 .

TABLE 3.

PARAMETERS OF THE SIMULATION WITH MINIMUM AND MAXIMUM BOUNDARIES.

\begin{tabular}{lrrr}
\hline \multicolumn{4}{c}{ Simulation Parameters } \\
\hline Parameter & Min & Max \\
\hline BN & 0 & 9 \\
Angle & 1 & 4 \\
Draft & 9.0 & 12.0 \\
Vs Init. & 19 & 23.5 \\
\hline
\end{tabular}


After the generation of 5000 samples of the simulation input, the results in the output side are filtered per $\mathrm{C}_{\mathrm{pv}}$ bin. Extreme values are the first to be eliminated, and then the results out of the range of dense recorded data $\mathrm{C}_{\mathrm{pv}}$ range following afterward.

\section{RESULTS AND DISCUSSION}

After multiple attempts of generating samples and filtering, an optimal set of generated output results are obtained. After the application of the steps above, it is possible to analyze and compare the simulation results with the processed ship recorded data. To observe the comparison at a larger scale, the immediate action is to plot the set of results to a graph in comparison with each vessel.

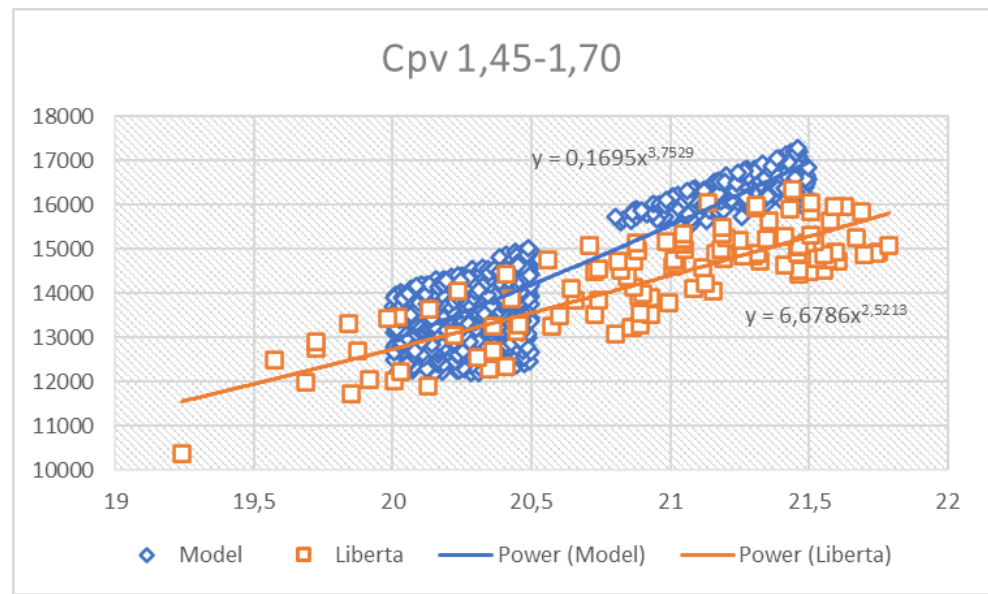

Figure. 4. Comparison of Liberta recorded data with model results (Overall)

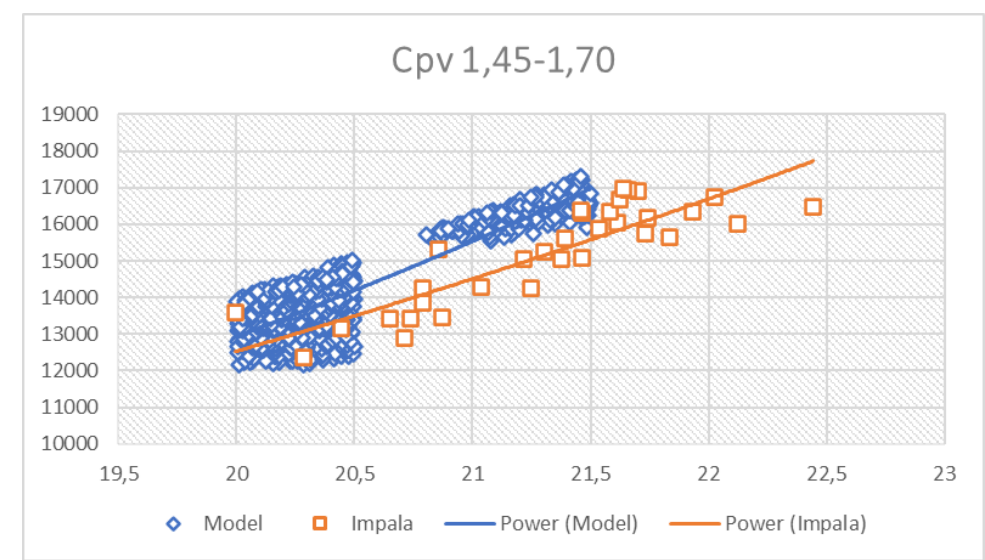

Figure. 5. Comparison of Impala recorded data with model results (Overall)

It can be inferred from Figure 4. and figure 5. that the average line of the simulation results is situated quite close to the average line of the model results. However, the data samples for Impala are significantly fewer compared to its counterpart, so its relevancy is more questionable. One trait that both comparisons show is the increase in the model average line's deviation from the ships' recorded data average lines. To see the percentage error, the following expression can be used:

$$
\delta=\left|\frac{v_{A}-v_{E}}{v_{E}}\right| \cdot 100 \%
$$

From the application of the error percentage formula, the diagram in Figure 6. is obtained. The error count of the average line comparison suggests that at the speed of approximately 19,7 knots, the average model-simulation results are close to the actually recorded observation. One conclusion of the model that can be inferred from this phenomenon is that the power-speed behavior from the current setup does not perfectly reflect the actual ship power-speed relation. 


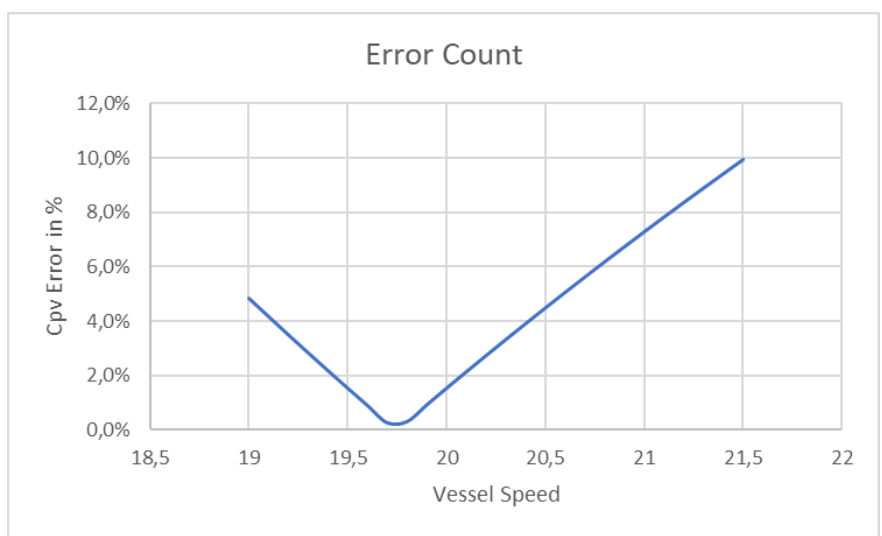

Figure. 6. Error Count of comparison between simulation results and Liberta data

This conclusion is strengthened by the results in Figure 7., where plotting the function of the power of both average lines results in two lines that intersect at approximately 19,7 knots, however, stray away when at higher and lower speeds.

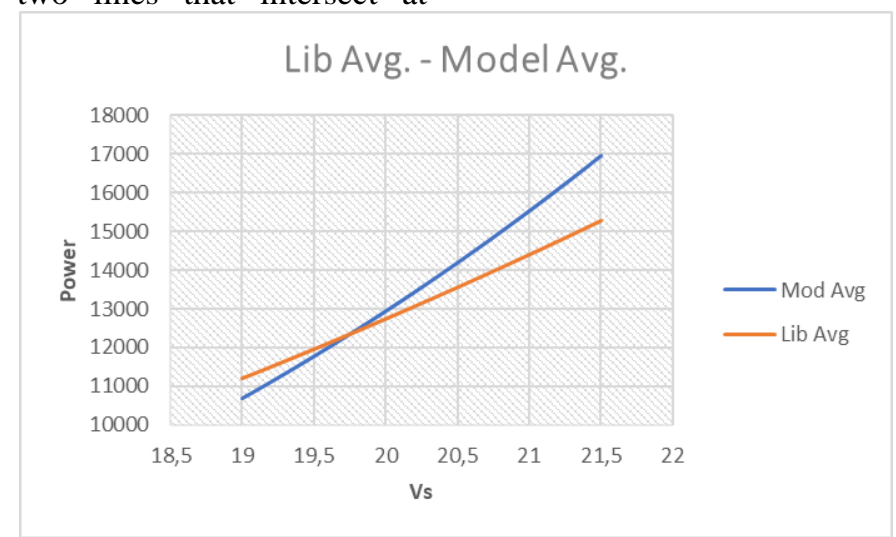

Figure. 7. Comparison between the Model average and Liberta average equations at average operation speed

By using the function of power from the average line of the filtered model simulation results and the ship recorded observation data, a plot to see a rough

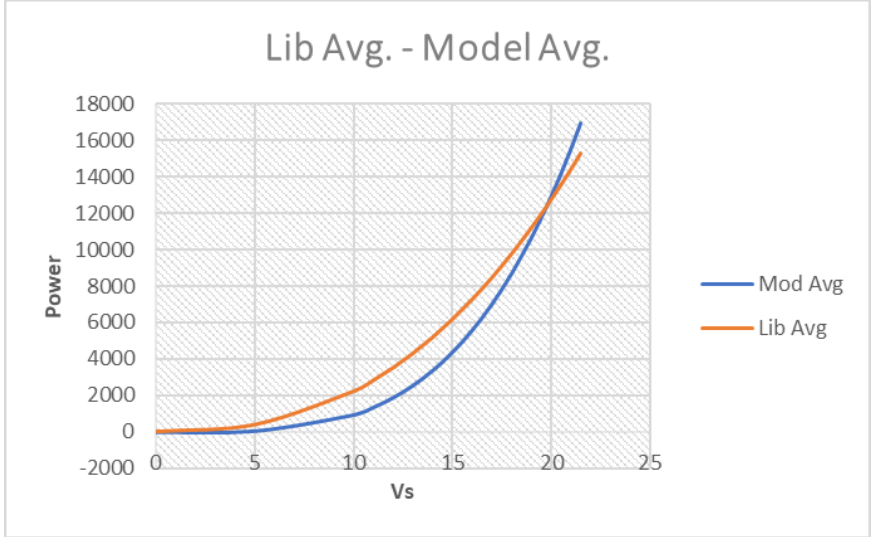

Figure. 8. Comparison of Model analysis average line with the ship average line at a larger scale

Figure 8. shows that both of the average lines behave relatively similar, however at the middle range of the plot, the error is larger. This is naturally the effect of the model being based on the available operational data, where most of the samples of data fall in the 19 knots 22 knots. Operational data samples outside that range are too few to be considerable. comparison of the average value of the current model setup and actual data can be done. 


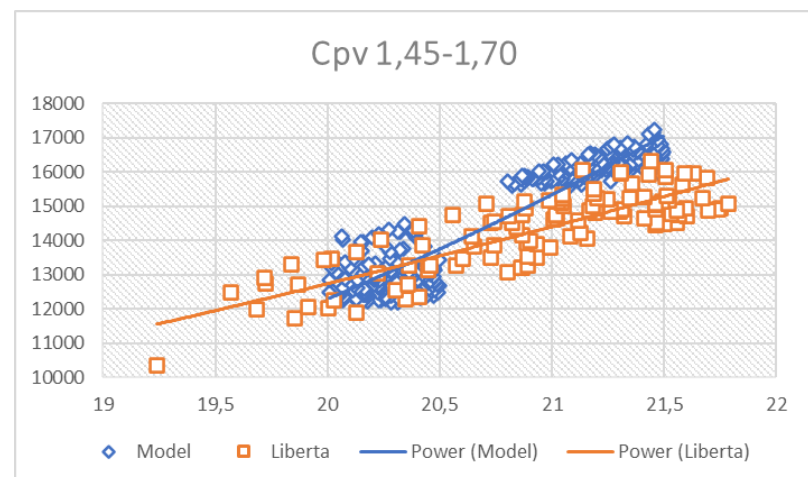

Figure. 9. Comparison of the average lines under a smaller scope (Draft 9,0 m-9,5 m)

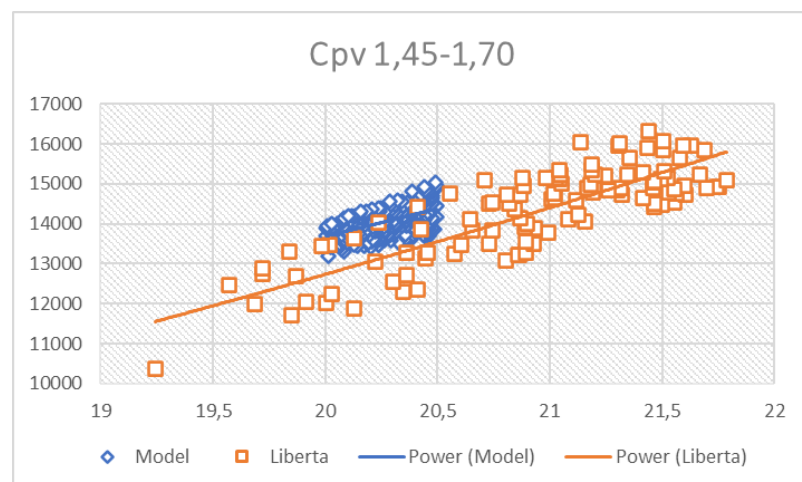

Figure. 10. Comparison of the average lines under a smaller scope (Draft $10 \mathrm{~m}-10,5 \mathrm{~m}$ )

From Figure 9., the intersection which was not seen in the overall graph (refer to Figure 4.) is present in this scope of analysis. This suggests that the current modelsimulation setup is well adjusted to this range of the draft. A far-fetched conclusion may also be inferred that the average load draft of the ship has operated in is in this range.

Figure 10. shows that at a higher draft range the estimated ship power deviates more, and the lack of compatible samples at higher speeds suggests that with the current model setup this range of draft is less accurate.

In operational data-based research by Lakshmynarayanana and Hudson to acquire added power estimation from the derivation of the total operational power, the classic semi-empirical calm water resistance estimation (Holtrop method) also shows an increasingly larger deviation at higher drafts.

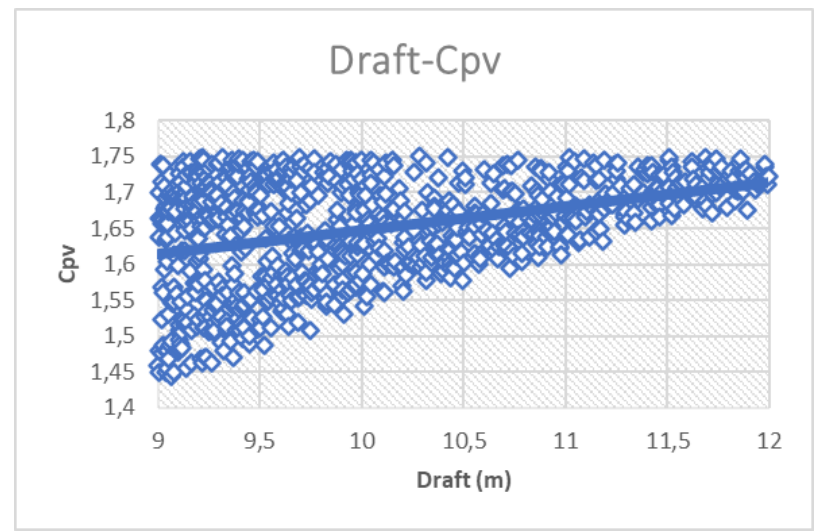

Figure .11. Overall Draft- $\mathrm{C}_{\mathrm{pv}}$ sample plot and average line

Principally, the increase of draft shall raise the immediate total resistance of the ship according to theory. This is proven true in the model-simulation as seen in Figure 11., where albeit the samples generated vary in $C_{p v}$ range, the average line follows a trend of increase.

When considering the application of this model, observing Figure 6. the maximum error in the model's limited range reaches a maximum of $10 \%$. The applicability of this model for a professional setting in evaluating voyage operations may not be recommended. However, the behavior and proximity of the results deem it reasonable to be considered as a reference, and especially for study or further research on the same topic. 


\section{CONCLUSION}

A model to predict estimation of the power increase in rough weather at various Beaufort Numbers, wind \& wave directions, speed settings, and various load drafts are possible to be created using the classic calm water resistance estimation theory along with the Kwon method of approximating added resistance due to wind and waves, with tolerable applicability for reference, study and further academic research on the topic of ship operations data-based modeling.

A theoretical stochastic simulation for ship databased modeling proves to provide value in testing and benchmarking when applied with sufficient analysis and iterations at different parametrical setups. It can be used to assess the behavior of the model.

The lack of data samples from recorded operational data at speeds outside the average operational range limit the model to a certain speed range, from 19 knots to 23 knots. There is no means of verification of lower speeds if applying the current model setup. It can be concluded that not only the quantity of data is required, but also the quality (especially considering the variety of data) of the data should be considered.

The variety of draft load is determinant in benchmarking the model with actual operational records, this is initially seen when comparing the results of the classic calm water resistance estimation at the maximum draft. At such conditions, the available ship data does not comply. At the latter parts of the analysis, the overall recorded data is compatible within the model's limited range, especially in the range of 9,0 to 9,5 meters, where the average ship operation line and the model simulation results average line even intersect at a point.

\section{ACKNOWLEDGMENTS}

The authors appreciate the privilege and opportunity to conduct research on the material. Support from the supervisors and others are also acknowledged and appreciated, enabling the improvement of learning and developing a better understanding of Marine Engineering.

\section{REFERENCES}

[1] O. M. Faltinsen, K. J. Minsaas, N. Liapis, and S. O. Skjordal, "Prediction of resistance and propulsion of a ship in a seaway," in 13th symposium on naval hydrodynamics, 1980.

[2] S. A. Harvald, Resistance and Propulsion of Ships, John Wiley \& Sons, 1983.

[3] A. F. Molland, S. R. Turnock and D. A. Hudson, Ship Resistance and Propulsion: Practical Estimation of Ship Propulsive Power, New York: Cambridge University Press, 2011.

[4] International Towing Tank Conference, "ITTC Recommended Procedures," 2002.

[5] H. O. Kristensen and M. Lützen, "Prediction of Resistance and Propulsion Power of Ships," Technical University of Denmark, 2013. [6] J. Holtrop and G. Mennen, "An Approximate Power Prediction Method," International Shipbuilding Progress, vol. 29, no. 335, 1982. [7] The Open University, Waves, Tides and Shallow-Water Processes, Butterworth-Heinemann, 1999.

[8] M. Alexandersson, "A Study of Methods to Predict Added Resistance in Waves," KTH Centre for Naval Architecture, Stockholm, 2009.

[9] International Towing Tank Conference, "Recommended Procedures and Guidelines," 2014

[10] R. L. Townsin and Y. J. Kwon, "Approximate Formulae for the Speed Loss due to Added Resistance in Wind and Waves," R.I.N.A. Supplementary Papers, vol. 125, no. July, p. 199, 1983.

[11] Y. J. Kwon, "Speed loss due to added resistance in wind and waves," The Naval Architect, vol. 3, pp. 14-16, 2008.

[12] R. Billinton and R. N. Allan, Reliability Evaluation of Engineering Systems, New York: Springer US, 1992.

[13] J. Wittwer, "Monte Carlo Simulation Basics," 2004. [Online]. Available:

https://www.vertex42.com/ExcelArticles/mc/MonteCarloSimulation.ht ml. [Accessed 13 July 2020]

[14] J. W. Wittwer, "Vertex42," 1 June 2004. [Online]. Available: Vertex42.com. [Accessed 20 July 2020].

[15] Wikipedia, "CC 2500," 2019. [Online]. Available: https://de.wikipedia.org/w/index.php?title=CC_2500\&oldid=17262672 9. [Accessed 2005 2020].

[16] Wikipedia, "Warnow Cv 2500," 2019. [Online]. Available: https://de.wikipedia.org/w/index.php?title=Warnow_CV_2500\&oldid= 172549256. [Accessed 25 May 2020].

[17] P. A. Lakshmynarayanana and D. Hudson, "Estimating Added Power in Waves for Ships Through Analysis of Operational Data," Schwinkendorf, 2017. 